\title{
Effect of Tetrafluoromethane Plasma Treatment of PMMA on MCF-7 Cell Proliferation
}

\author{
Chih-Hsin Shih ${ }^{*}, 1$, Meng-Jiy Wang ${ }^{2}$, Chien-Hsing Lu ${ }^{3,4,5}$, Wei-Li Yuan ${ }^{1}$, Li-Qun Lai ${ }^{1}$, \\ Zong-Xin $\mathrm{Wu}^{1}$ and Chi-Jung Chang ${ }^{1}$
}

\author{
${ }^{I}$ Department of Chemical Engineering, Feng Chia University, 100 Wenhwa Road, Taichung, 40724, Taiwan \\ ${ }^{2}$ Department of Chemical Engineering, National Taiwan University of Science and Technology, 43, Sec. 4, Keelung \\ Road, Taipei, 106, Taiwan \\ ${ }^{3}$ Department of Obstetrics and Gynecology, Taichung Veterans General Hospital, 160, Sec. 3, Chung-Kang Rd., \\ Taichung, 40705, Taiwan \\ ${ }^{4}$ Institute of Biomedical Sciences, National Chung-Hsing University, Taichung, Taiwan \\ ${ }^{5}$ Department of Obstetrics and Gynecology, School of Medicine, National Yang-Ming University, Taipei, Taiwan
}

\begin{abstract}
Polymethyl methacrylate (PMMA) was surface modified by tetrafluoromethane $\left(\mathrm{CF}_{4}\right)$ plasma and its effect on the human breast cancer cells (MCF-7) adhesion and proliferation were investigated. The promotion of MCF-7 cell growth was positively and quantitatively related to the $\mathrm{CF}_{4}$ plasma modification as revealed by different characterizations. From ESCA analysis, it is revealed that $\mathrm{CF}_{4}$ plasma treatment chemically alters the capability of PMMA to adsorb proteins from cell culture medium, which is about four times comparing to that of pristine PMMA. In addition to chemical alteration, $\mathrm{CF}_{4}$ plasma also concurrently delivered physical modification by doubling the surface roughness, as observed by AFM analysis.
\end{abstract}

Keywords: Tetrafluoromethane plasma, surface modification, cell proliferation, MCF-7.

\section{INTRODUCTION}

Poly (methylmethacrylate) (PMMA) has been widely used as the material for substrates in biomedical application for its advantages of chemically inert, transparent, excellent mechanical properties, low cost, and ease of fabrication. It has been widely used in applications such as tissue engineering [1], microarrays [2], biosensors [3], and MEMS [4]. To tether the bioactive compounds to PMMA, surface modification methods, such as wet chemical method, ionized gas treatment, and UV radiation need to be conducted. Surface properties such as electrical charge, functional groups [5], and contact angle [6-7] play important roles on governing the response of biomolecules to the surface $[6,8$ $10]$.

Wet chemical method is a classical approach that can be performed at any laboratory without specialized equipment. It has been demonstrated that the PMMA surface can be activated by hydrolysis through sodium hydroxide or sulfuric acid [1, 11-13], followed by aminolysis using various diamines to introduce primary amines onto the PMMA surface. In recent years, plasma treatment has demonstrated to be an effective surface modification method. The desired functional groups were incorporated on the top layer of the PMMA surface by selecting appropriate plasma gases such

*Address correspondence to this author at the Department of Chemical Engineering, Feng Chia University, 100 Wenhwa Road, Taichung, 40724, Taiwan; Tel: 886 - 4 -24517250, Ext. 3680; Fax: 886 - 4-24510890;

E-mail: chshih@fcu.edu.tw as $\mathrm{Ar}, \mathrm{N}_{2}, \mathrm{O}_{2}$, or $\mathrm{CF}_{4}$. In addition, plasma polymerization can also be used in preparing thin films for coatings, immunosensors, and interfaces for biomaterials [14-16]. The advantages of plasma polymerized thin films include pinhole free, great homogeneity, mechanical, chemical, and adhesion properties [16].

PMMA has been used in a variety of biomedical applications such intraocular and contact lenses. The modification of PMMA surface plays important roles on cell adhesion and attachment. Researchers in the past had demonstrated methods to control cell adhesion on PMMA by incorporating the surface with heparin [17], poly(ethylene glycol) [18], RGD peptide [19], implanting positive fluorine [20], and oxygen plasma treatment [21].

In this work, the effect of $\mathrm{CF}_{4}$ plasma modified PMMA on cell proliferation was evaluated by complementary surface characterizations such as surface wettability, the Electron Spectroscopy for Chemical Analysis (ESCA), and atomic force microscopy (AFM). Human breast cancer cells (MCF-7) were used in this study in an effort to develop a microfluidic drug screening system.

\section{MATERIALS AND METHODS}

\subsection{Surface Modification}

The plasma treatment was carried out at the plasma chamber with constant pressure evacuated by a mechanical pump. Plasma was generated by applying power from a radio frequency generator (13.56 MHz). The PMMA surface modification was processed with pretreatment by using 
oxygen plasma with $10 \mathrm{sccm}$ flow rate for $10 \mathrm{~min}$ at applied power of 20 Watt. $\mathrm{CF}_{4}$ plasma treatment was then carried out by introducing gas flow at $10 \mathrm{sccm}$ with the total pressure at $100 \mathrm{mTorr}$ for $1 \mathrm{~min}$.

In addition to $\mathrm{CF}_{4}$ plasma modified PMMA, pristine PMMA and a tissue culture polystyrene (TCPS) dish (Nunclon ${ }^{\mathrm{TM}}$ ) were used as the reference materials in order to demonstrate the effect of $\mathrm{CF}_{4}$ plasma treatment on MCF-7 cell proliferation.

\subsection{Cell Culture}

The MCF-7 human mammary epithelial cell line, available from ATCC, was used in cell culture experiments. The cells were incubated with DMEM/F-12 medium (Invitrogen) at $37^{\circ} \mathrm{C}$ in a humidified $5 \% \mathrm{CO}_{2}$ incubator for $24 \mathrm{~h}$. A suspension of $6 \times 10^{4}$ cells $/ \mathrm{ml}$ was prepared in this experiment.

\subsection{Cell Proliferation Test}

The number of living cells in culture was quantified using the CellTiter 96 aqueous one solution cell proliferation assay (Promega). Test wells were fabricated by attaching a PDMS block (with wells) to the modified PMMA surfaces. MCF-7 cell suspension in medium of $500 \mu \mathrm{L}\left(3 \times 10^{4}\right.$ cells $)$ were placed in each well and incubated at $37^{\circ} \mathrm{C}$ with $5 \%$ $\mathrm{CO}_{2}$ for $1,4,12$, and $24 \mathrm{~h}$. After incubation, the medium in each well was removed and a mixture of $10 \mu \mathrm{L}$ MTS reagent and $100 \mu \mathrm{L}$ of medium was added to each well and incubated for $15 \mathrm{~min}$. An amount of $100 \mu \mathrm{L}$ of solution in each well was withdrawn and injected into wells in a microtiter plate, respectively. Optical density (OD) in each well was measured at $492 \mathrm{~nm}$ using a Microplate reader (Triad, Dynex Technologies). In addition, the morphology of cells was also examined by using an inverse optical microscope (IX71, Olympus).

\subsection{Surface Protein Content Analysis}

The sample plates were prepared as $1 \times 1 \mathrm{~cm}^{2}$ and were washed by ethanol and deionized water, followed by nitrogen gas flow. The sample plates were immersed in cell culture medium for $24 \mathrm{~h}$ and then dried in laminar flow and kept in desiccator prior use. The surface characterizations were performed by water contact angle (WCA), ESCA, and AFM. The static contact angle measurement was carried out with a goniometer. At least five contact angle measurements were performed for each sample. Elemental and compositional analyses were carried out using X-ray photoelectron spectroscopy (Thermo VG Scientific Theta Probe) with $\mathrm{Al}(1486.6 \mathrm{eV})$ and $\mathrm{Mg}(1253.6 \mathrm{eV})$ as sources of X-rays. Morphological observations of protein adsorbed samples were carried out by Atomic Force Microscopy (Digital Instruments Nanoscope III Atomic Force Microscopy, Veeco Ltd.).

\subsection{Statistical Analysis}

The cell proliferation results were statistically analyzed by employing one-way analysis of variance (ANOVA) executed by Minitab ${ }^{\circledR}$ statistical software. Fisher's pairwise comparison test was applied to compare the effect of different surfaces (TCPS, pristine PMMA and $\mathrm{CF}_{4}$-plasma- treated PMMA) utilized to grow MCF-7 cells in order to determine which sample yields higher cell number, indicated by: $(*)=p<0.05 ;(* *)=p<0.01$; and $(* * *)=p<0.001$.

\section{EXPERIMENTAL RESULTS}

\subsection{Cell Proliferation}

MCF-7 cells were seeded and incubated for $24 \mathrm{~h}$ in the wells in which the surfaces of PMMA were modified. The proliferation of cells was measured by conducting MTS assay and the results were shown in Fig. (1). Compared to TCPS standard and the pristine PMMA, the $\mathrm{CF}_{4}$ plasma modified PMMA exhibited the highest growth rate for MCF7 cells. For the cells incubated for $12 \mathrm{~h}$, PMMA surface modified by $\mathrm{CF}_{4}$ plasma improved the growth of $\mathrm{MCF}-7$ cells by $73.6 \%$, and $89.3 \%$, than that on TCPS and pristine PMMA, respectively. After $24 \mathrm{~h}$ incubation, although the increment was not as significant as that of $12 \mathrm{~h}$ incubation time, a moderate cell density enhancement for the MCF-7 cells on the $\mathrm{CF}_{4}$ plasma modified PMMA was $9.9 \%$ and $31.7 \%$, compared to TCPS and pristine PMMA, respectively. The statistic analyses clear demonstrate that the $\mathrm{CF}_{4}$ plasma can improve the growth of MCF-7 cells than that on TCPS and pristine PMMA, for both incubation duration of 12 and $24 \mathrm{~h}$, as indicated by $p<0.001$.

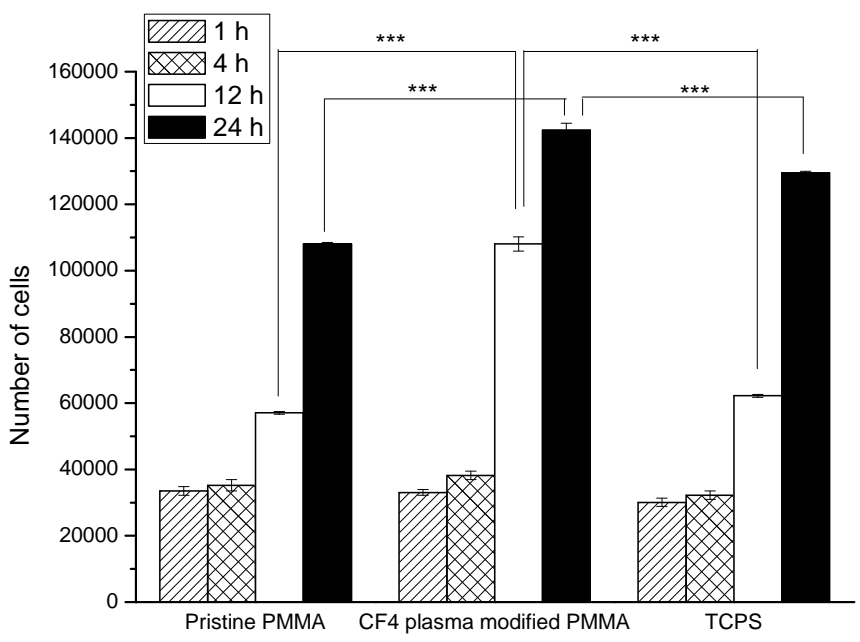

Fig. (1). MCF-7 cell count on various surfaces after incubation for $1,4,12$, and 24 hours. $(*)=p<0.05 ;(* *)=p<0.01 ;(* * *)=p$ $<0.001$.

This analytical observation by MCF-7 cells proliferation test was also supported by physical appearance as evidenced by optical microscopy images (Fig. 2). Superior coverage and adhesion of MCF-7 cells were revealed on $\mathrm{CF}_{4}$ plasma treated PMMA, compared to that on pristine PMMA and TCPS surfaces. Different MCF-7 cell morphology was also perceived. On pristine PMMA, the cells were grown apart, with small amount of proliferated cells and mostly were in round shape, suggesting less active growth preference on pristine PMMA. Less round and more proliferated cells grown were observed on TCPS, the standard for cell culture substrate. Astounding proliferation was demonstrated on $\mathrm{CF}_{4}$ plasma modified PMMA, with the least amount of round cells, and very intense proliferated MCF-7 cells that outperform pristine PMMA, and even TCPS. 
(a)

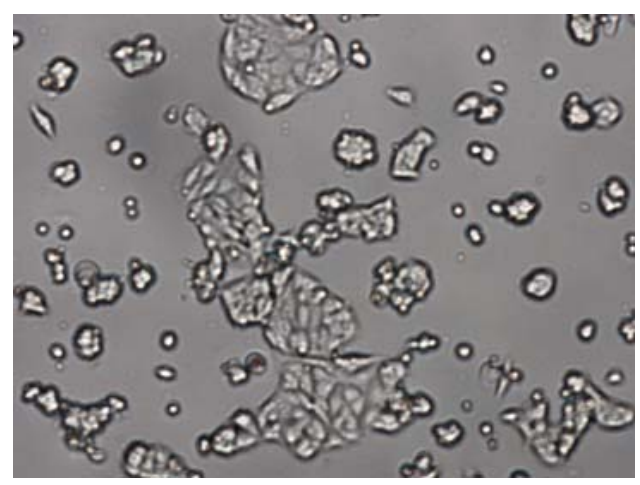

(b)

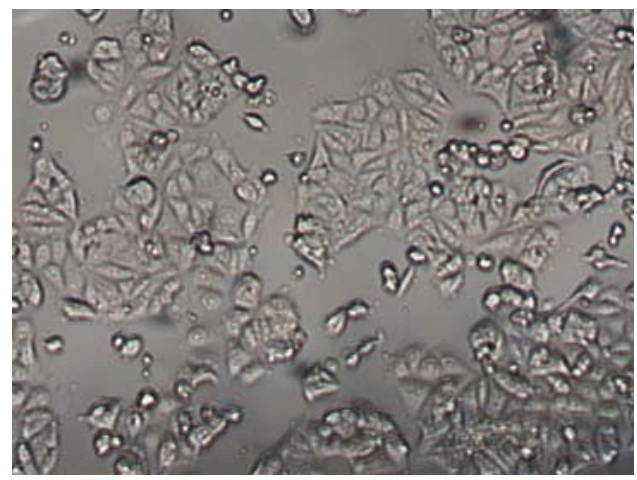

(c)

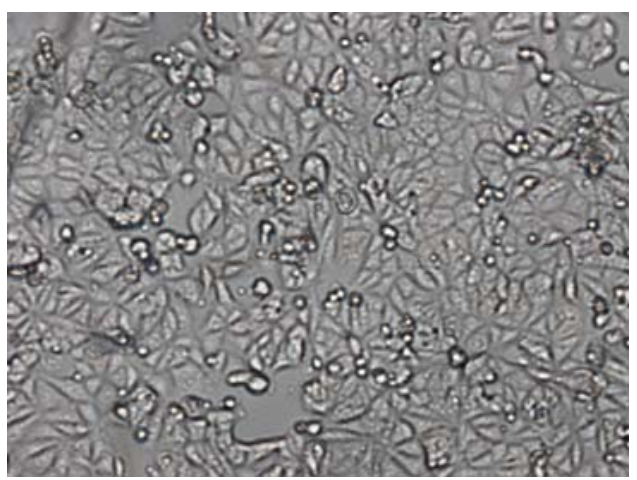

Fig. (2). Microscopic pictures of MCF-7 cells grown on various surfaces after incubation for 24 hours: (a) pristine PMMA; (b) TCPS; and (c) $\mathrm{CF}_{4}$ plasma modified PMMA.

\subsection{Surface Characterization}

From the results of both cell proliferation and optical microscopy, it is obvious that after $\mathrm{CF}_{4}$ plasma treatment, the MCF-7 cell proliferation on PMMA was greatly improved. To further explore this phenomenon, it is necessary to examine the effect of protein adsorption, which was originated from the cell culture medium, occurred on the modified surfaces.

Water contact angle measurements were used to physically examine the protein adsorption on different substrates. Pristine PMMA showed hydrophobic property with water contact angle of $96^{\circ}$ (Table 1). However, the samples showed very different water contact angles after immersed in cell culture medium (CCM). After the PMMA was immersed in $\mathrm{CCM}$ at $37^{\circ} \mathrm{C}$ for $24 \mathrm{~h}$, water contact angle was changed from $96^{\circ}$ to $26^{\circ}$, which was resulted from the protein adsorption during the incubation in cell culture medium. Similar results were also observed for the $\mathrm{CF}_{4}$ plasma treated PMMA. The water contact angle for the PMMA surface after $\mathrm{CF}_{4}$ plasma treatment was more than $107^{\circ}$, indicating a hydrophobic surface was resulted. After incubation in CCM, the surface water contact angle decreased to about $29^{\circ}$. The results indicated that protein immobilization during $\mathrm{CCM}$ incubation brought similar water contact angle on different surfaces.

Because the water contact angle results indicated that the physical observations could not evidently describe the difference in protein adsorption capability caused by $\mathrm{CF}_{4}$ plasma treatment. Additional analyses to evaluate the surface composition were therefore performed to confirm the effect of $\mathrm{CF}_{4}$ plasma to the surface.

ESCA analyses were carried out for the pristine PMMA, and PMMA treated by $\mathrm{CF}_{4}$ plasma. All samples were incubated in cell culture medium for $24 \mathrm{~h}$ to observe the protein adsorption. Since the pristine PMMA is composed by $74.5 \% \mathrm{C}, 25.5 \% \mathrm{O}$ and no nitrogen, $\mathrm{N}$ 1s content provided by ESCA analyses can be utilized as a useful indication for the incorporation of proteins from cell culture medium.

After immersed in CCM for $24 \mathrm{~h}$, pristine PMMA showed $2.85 \%$ of nitrogen (Table 2), which indicated

Table 1. Water Contact Angle Measurements

\begin{tabular}{|c|c|c|c|c|}
\hline & Pristine PMMA & PMMA Immersed in CCM & $\mathbf{C F}_{4}$ Plasma Treated PMMA & $\mathbf{C F}_{4}$ Plasma Treated PMMA After Immersed in CCM \\
\hline \hline $\begin{array}{c}\text { Average } \\
\text { water } \\
\text { contact angle } \\
\text { (degree) }\end{array}$ & $95.92 \pm 2.26$ & $25.86 \pm 9.70$ & $107.23 \pm 1.81$ & $28.58 \pm 5.69$ \\
\hline
\end{tabular}


Table 2. Total Surface Chemical Composition from ESCA Analyses Wide Scan

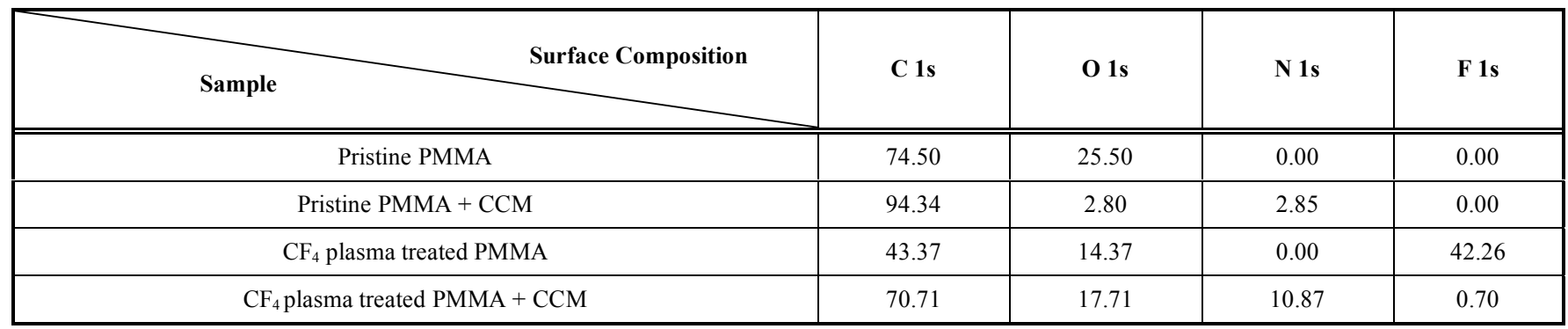

limited amount of protein was incorporated on the surfaces of pristine PMMA. On the other hand, the $\mathrm{CF}_{4}$ plasma treatment altered the PMMA surface significantly that the surface composition revealed $43.37 \%$ of carbon, $14.37 \%$ of oxygen and $42.26 \%$ of fluorine. After immersed in CCM, the nitrogen component increased to $10.87 \%$ on the $\mathrm{CF}_{4}$ plasma treated PMMA, almost four times than that of pristine PMMA, which indicated that protein adsorption was enhanced significantly by the fluorine containing surface.

Besides chemical analysis, nanometer-scale surface roughness measurement was also conducted to elucidate the effect of $\mathrm{CF}_{4}$ plasma on the surface morphology of PMMA. AFM was utilized to analyze surface topography for pristine PMMA and $\mathrm{CF}_{4}$ plasmas modified PMMA before and after incubation in culture medium for $24 \mathrm{~h}$. The threedimensional images of the surfaces were shown in Fig. (3) and the surface topography was quantified by the surface roughness (Table 3). AFM results showed that the pristine PMMA have a relatively smooth surface, with a roughness of $2.28 \mathrm{~nm}$ (Fig. 3a). After being immersed in cell culture medium, the roughness of pristine PMMA increased to 4.5 $\mathrm{nm}$ (Fig. 3b), which seemed to indicate that the rougher surface was resulted from protein adsorption. On the other hand, the average roughness of the $\mathrm{CF}_{4}$ plasma treated PMMA was $3.59 \pm 0.40 \mathrm{~nm}$ (Fig. 3c), which is close to pristine PMMA. This showed that $\mathrm{CF}_{4}$ plasma treatment only modified the outermost layer of the surface without resulting in significant change of surface morphology. After incubated in cell culture medium, the surface roughness of the plasma treated PMMA increased to $9.40 \pm 0.63 \mathrm{~nm}$, which seemed to indicate that more protein was incorporated on the surface of the $\mathrm{CF}_{4}$ plasma modified PMMA than the pristine PMMA.
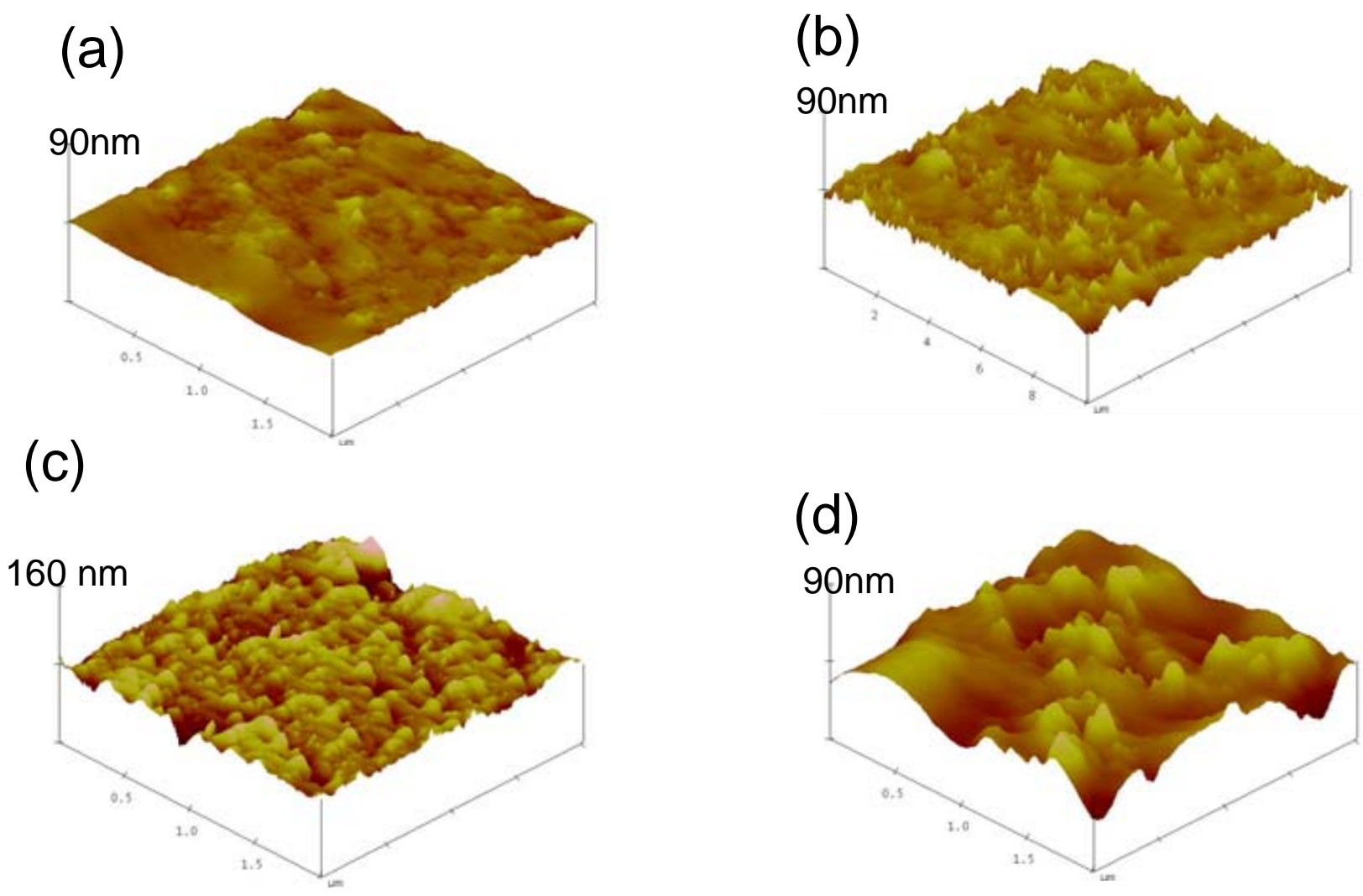

Fig. (3). AFM 3-dimensional images of the samples as follows: (a) pristine PMMA; (b) PMMA + cell culture medium; (c) $\mathrm{CF}_{4}$ plasma modified PMMA; and (d) $\mathrm{CF}_{4}$ plasma modified PMMA + cell culture medium. 
Table 3. Surface Roughness Calculated by AFM Analyses

\begin{tabular}{|c|c|c|c|c|}
\hline Sample & Pristine PMMA & PMMA + CCM & $\mathbf{C F}_{4}$ Plasma Treated PMMA & CF $_{4}$ Plasma Treated PMMA + CCM \\
\hline \hline Average roughness $(\mathrm{nm})$ & $2.28 \pm 0.25$ & $4.50 \pm 0.40$ & $3.59 \pm 0.40$ & $9.40 \pm 0.63$ \\
\hline
\end{tabular}

Table 4. Summary of Effect of $\mathrm{CF}_{4}$ Plasma Treatment and CCM Addition onto PMMA Surface Towards its Physical, Chemical, and Cell Growth Properties

\begin{tabular}{|c|c|c|c|c|c|c|}
\hline Surfaces & $\mathbf{C F}_{4}$ Plasma & CCM Addition & N-Content (\%) & WCA (Degree) & Roughness (nm) & MCF7 Cells/mL \\
\hline \hline Pristine PMMA & -1 & +1 & 2.85 & 26 & 4.5 & 108000 \\
\hline $\mathrm{CF}_{4}$ treated PMMA & +1 & +1 & 10.87 & 29 & 9.4 & 142000 \\
\hline
\end{tabular}

According to the results of contact angle, ESCA and AFM analyses, proteins in cell culture medium play key roles on promoting cell proliferation. The $\mathrm{CF}_{4}$ plasma treatment greatly promoted the protein adsorption on PMMA surface, which was proved clearly by the reduction of water contact angle, the increment of nitrogen content, and the surface morphology. Bacakova et al. [22] also showed that fluorine ions implanted polyethylene improves adhesion and growth of both endothelial cells and vascular smooth muscle cells. The extracellular matrix adsorbed to the polymer from the culture medium serum contributed to the cell adhesion.

\section{DISCUSSION}

The improved capability of protein adsorption on $\mathrm{CF}_{4}$ plasma treated PMMA revealed by ESCA explained the different growth rate of MCF-7 cells. The $2.85 \%$ protein adsorption capacity on pristine PMMA demonstrated MCF-7 growth of $10.8 \times 10^{4}$ cells $/ \mathrm{ml}$, whereas the growth on $\mathrm{CF}_{4}$ plasma treated one, with $10.87 \%$ protein adsorption capacity, accounted for $14.2 \times 10^{4}$ cells $/ \mathrm{ml}$. The improvement in MCF7 cell growth is about $4.2 \times 10^{3}$ cells for every $1 \%$ of increased amount of adsorbed protein onto the surface. Further experiment to explore and quantify the cell growth improvement as effect of different $\mathrm{CF}_{4}$ plasma treatment parameters (power, flowrate, duration, etc.) are still undergoing.

Moreover, the effects of $\mathrm{CF}_{4}$ plasma treatment and $\mathrm{CCM}$ addition towards the physical and chemical modification of PMMA and its influence to the MCF-7 cell growth were summarized in Table 4. It is clearly revealed that although $\mathrm{CF}_{4}$ plasma treatment did not alter the hydrophobicity of PMMA much, it promoted protein adsorption (as detected by ESCA) and enhanced the surface area (increased roughness measured by AFM), and showed progressed growth of MCF7 cells. It is noted that the effect of protein from CCM addition also brought the same trend that of $\mathrm{CF}_{4}$ plasma treatment which is currently a research topic ongoing in our group.

\section{CONCLUSIONS}

In this study, evaluation of the effect of $\mathrm{CF}_{4}$ plasma treatment of PMMA on MCF-7 cell proliferation was conducted. We discovered that interactions between MCF-7 cells and PMMA substrates were significantly enhanced by $\mathrm{CF}_{4}$ plasma treatment and proven statistically. The carbonfluorine functionalities generated via $\mathrm{CF}_{4}$ plasma treatments were shown to effectively promote cell proliferation after $24 \mathrm{~h}$ of cultivation.

The rationale of cell count enhancement was further identified to be highly associated with the adsorption of proteins in cell culture media onto PMMA surfaces by ESCA and AFM analyses. In summary, this study revealed that $\mathrm{CF}_{4}$ plasma assisted the incorporation of protein from cell culture medium which later promoted the MCF-7 cell growth in both qualitative and quantitative manners.

\section{ACKNOWLEDGEMENTS}

The authors thank Feng Chia University and Taichung Veterans General Hospital (TCVGH-FCU988205) for their financial support of this project.

\section{REFERENCES}

[1] Tanahashi M, Yao T, Kokubo T, et al. Apatite coated on organic polymers by biomimetic process: Improvement in its adhesion to substrate by $\mathrm{NaOH}$ treatment. J Appl Biomater Biomech 1994; 5(4): 339-47.

[2] Fixe F, Dufva M, Telleman P, Christensen CBV. One-step immobilization of aminated and thiolated DNA onto poly(methylmethacrylate) (PMMA) substrates. Lab Chip 2004; 4(3): 191-5.

[3] Long TM, Prakash S, Shannon MA, Moore JS. Water-vapor plasma-based surface activation for trichlorosilane modification of PMMA. Langmuir 2006; 22(9): 4104-9.

[4] Qu H, Wang H, Huang Y, et al. Stable microstructured network for protein patterning on a plastic microfluidic channel: strategy and characterization of on-chip enzyme microreactors. Anal Chem 2004; 76(21): 6426-33.

[5] Faucheux N, Schweiss R, Lützow K, Werner C, Groth T. Selfassembled monolayers with different terminating groups as model substrates for cell adhesion studies. Biomaterials 2004; 25(14): 2721-30

[6] Ozcan C, Zorlutuna P, Hasirci V, Hasirci N. Influence of oxygen plasma modification on surface free energy of PMMA films and cell attachment. Macromol Symp 2008; 269(1): 128-37.

[7] Tamada Y, Ikada Y. Fibroblast growth on polymer surfaces and biosynthesis of collagen. J Biomed Mater Res 1994; 28(7): 783-9.

[8] Chen G, Imanishi Y, Ito Y. Effect of protein and cell behavior on pattern-grafted thermoresponsive polymer. J Biomed Mater Res A 1998; 42(1): 38-44.

[9] Matsuda T, Sugawara T. Control of cell adhesion, migration, and orientation on photochemically microprocessed surfaces J Biomed Mater Res A 1996; 32(2): 165-73.

[10] Mrksich M, Chen CS, Xia Y, Dike LE, Ingber DE, Whitesides GM. Controlling cell attachment on contoured surfaces with selfassembled monolayers of alkanethiolates on gold. Proc Natl Acad Sci USA 1996; 93(20): 10775-8.

[11] Holmberg K, Hyden H. Methods of immobilization of proteins to polymethylmethacrylate. Prep Biochem Biotechnol 1985; 15(5): 309-19. 
[12] Varma HK, Sreenivasan K, Yokogawa Y, Hosumi A. In vitro calcium phosphate growth over surface modified PMMA film. Biomaterials 2003; 24(2): 297-303.

[13] Brown L, Koerner T, Horton JH, Oleschuk RD. Fabrication and characterization of poly(methylmethacrylate) microfluidic devices bonded using surface modifications and solvents. Lab Chip 2006; 6(1): 66-73.

[14] Hamerli P, Weigel T, Groth T, Paul D. Enhanced tissuecompatibility of polyethylenterephtalat membranes by plasma aminofunctionalisation. Surface Coat Technol 2003; 10(174-175): 574-8.

[15] Akdogan E, Cökeliler D, Marcinauskas L, Valatkevicius P, Valincius V, Mutlu M. A new method for immunosensor preparation: Atmospheric plasma torch. Surface Coat Technol 2006; 201(6): 2540-6.

[16] Muguruma H, Karube I. Plasma-polymerized films for biosensors. Trends Anal Chem 1999; 18(1): 62-8.

[17] Tognetto D, Ravalico G. Inflammatory cell adhesion and surface defects on heparin-surface-modified poly(methyl methacrylate) intraocular lenses in diabetic patients. J Cataract Refract Surg 2001; 27(2): 239-44.

[18] Kim MK, Park IS, Dal Park H, et al. Effect of poly(ethylene glycol) graft polymerization of poly(methyl methacrylate) on cell adhesion - In vitro and in vivo study. J Cataract Refract Surg 2001; 27(5): 766-74.

[19] Patel S, Thakar RG, Wong J, McLeod SD, Li S. Control of cell adhesion on poly (methyl methacrylate). Biomaterials 2006; 27(14): 2890-7.

[20] Li DJ, Cui FZ, Gu HQ. F+ ion implantation induced cell attachment on intraocular lens. Biomaterials 1999; 20(20): 188996.

[21] Ozcan C, Hasirci N. Plasma modification of PMMA films: surface free energy and cell-attachment studies. J Biomater Sci Polym Ed 2007; 18(6): 759-73.

[22] Bacakova L, Mares V, Lisa V, Svorcik V. Molecular mechanisms of improved adhesion and growth of an endothelial cell line cultured on polystyrene implanted with fluorine ions. Biomaterials 2000; 21(11): 1173-9.

This is an open access article licensed under the terms of the Creative Commons Attribution Non-Commercial License (http://creativecommons.org/licenses/by-nc/ $3.0 /$ ) which permits unrestricted, non-commercial use, distribution and reproduction in any medium, provided the work is properly cited. 